\title{
COLOR MEASUREMENTS OF ELECTROPLATED GOLD FILM ON HULL CELL PANELS
}

\author{
C.W. Zanariah C.W. Ngah ${ }^{1}$ and Norita Mohamed ${ }^{2}$ \\ ${ }^{1}$ Senior Lecturer, Faculty of Science \& Technology, Universiti Sains Islam Malaysia, Bandar Baru Nilai, 71800 Nilai, \\ Negeri Sembilan, Malaysia, cw.zanariah@usim.edu.my \\ ${ }^{2}$ Professor, School of Chemical Sciences, Universiti Sains Malaysia, 11800 Minden, Pulau Pinang, Malaysia, \\ mnorita@usm.my
}

\begin{abstract}
The method of measuring the color of electrodeposited gold films on hull cell panels is described. Guidelines are also given for the selection of locations for measurements on a panel as well as for reporting the appropriate $L^{*} a *$ and $b^{*}$ values for use in calculating the color difference in terms of $\Delta E^{*}{ }_{a b}$ between the measured locations. By developing the control charts of $\Delta E^{*}{ }_{a b}$ range and average, the color tolerances between locations on a gold electrodeposited hull cell panel that have a bright appearance observed was established. The $\Delta E^{*}{ }_{a b}$ for an 'acceptable' color match was found to be from 2.59 to 5.74. For the purpose of reporting the $L^{*}$, a* and $b^{*}$ value for an electroplated hull cell panels, the average value of $L^{*} a^{*}$ and $b^{*}$ measured from all locations in a panel should be used.
\end{abstract}

Index Terms: color measurements, electrodeposited gold film, and hull cell

\section{INTRODUCTION}

Hull Cells have been an indispensable tool in the electroplating process. This gadget allows the plater to evaluate the bath conditions by inspecting the panel and make corrections to the bath properties [2,3]. The Hull cell or other plating tests are very useful in monitoring additives and contamination levels as well as the overall performance characteristics, especially brightness, if they are made on a regular basis and their results are correlated with production experience [3, 4]. Only an experienced operator is able to determine the approximate limits of bright density range of a panel [7].

The brightness observed on an electroplated Hull cell panel has always been the determining factor in assessing whether the compositions of chemicals in the electroplating solution are in a correct ratio or not. This will fulfill the aspect of obtaining workable current density ranges for a particular electroplating solution. But the question arises as to whether there is any color differences observed throughout the workable current density range? Can acceptable color tolerances be established to determine whether the color of a panel matches another panel electroplated from an electroplating solution containing slightly different bath properties in terms of chemical concentration and composition?

CIELAB uniform color scales method which expresses the color as three-dimensional coordinates $\mathrm{L}^{*}, \mathrm{a}^{*}$ and $\mathrm{b}^{*}$, was used to calculate the color differences observed in the electroplated Hull cell panels produced in this study. Where $\mathrm{L}^{*}$ variables represent color brightness, with L0 representing black and L100 representing white. The "a" variables represents a color's red to green color components, where a fully red color would be expressed as: a 100. A fully green color would be expressed as: a- 100. And "b" represents the color's yellow to blue, ranging from 100 to -100 , as illustrated in Fig. $1[5,6,13]$. The three numbers can be used to plot the exact coordinates of any specific color hue on the CIELAB chart. This system facilitates the measurement of the difference between two color specimens $\left(\mathrm{L} 1^{*}, \mathrm{a} 1^{*}, \mathrm{~b} 1^{*}\right.$, and L2*, a2*, b2). It can be easily calculated as the vectorial color distance between them and is therefore expressed as single parameter, $\Delta \mathrm{E}^{*}$. The total difference between two samples of color co-ordinates $\mathrm{L} 1 *, \mathrm{a} 1 *$, and $\mathrm{b} 1 *$, and $\mathrm{L} 2 *, \mathrm{a} 2 *$ and $\mathrm{b} 2 *$, respectively, is given as:

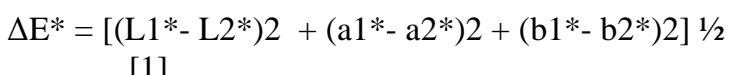
[1]

$\Delta \mathrm{E}^{*}$ is a quantitative measurement of color difference. This feature is of great use in quality control functions. The consistency of this system in measurements of karat gold has also being verified [8]. 


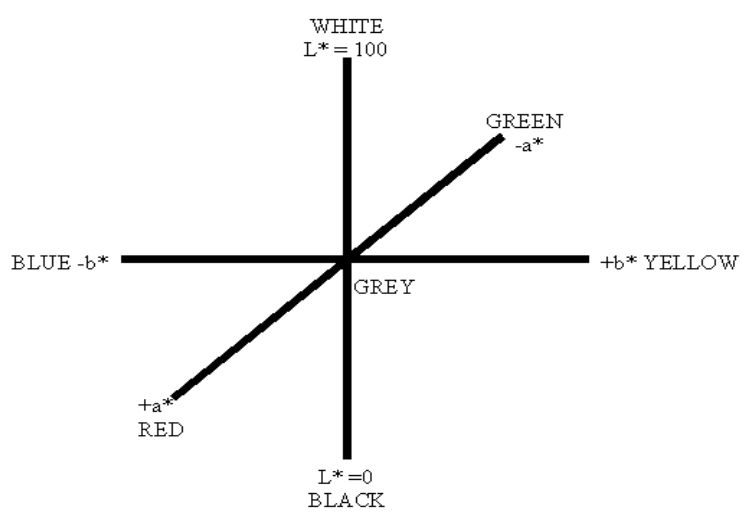

Figure1. Three-dimensional CIELAB system of orthogonal color co-ordinates

Control charts provide the basis by which we can reasonably (in a statistical sense) presume that a process is "in control" or "out of control". The difficult task in employing control charts is that actual analysis must be conducted manually. Proper analysis not only requires a thorough knowledge and understanding of the underlying distribution theories associated with control charts, but also the experience that only an expert can provide. While using the control charts, the judgment is usually left to the user [12]. Color attributes can be quantified in terms of $\Delta \mathrm{E}^{*}$; therefore control charts can be used to determine whether color deviations occurring in a panel or between panels electroplated using similar electroplating solutions are within the control process limit. In general, to construct the control charts, the $\mathrm{X}$ and $\mathrm{R}$ charts are used in conjunction with each other. The X-chart is used to monitor and control the process average while the $\mathrm{R}$ - chart is used to detect variations within a sample. In an $\mathrm{X}$ - chart, UCL, CL, and LCL are the usual notations for upper control limit, center line, and lower control limit respectively, where $\mathrm{UCL}$ and LCL were calculated from $\mathrm{X}$ as $\mathrm{UCL}=\mathrm{X}+3 \sigma(\mathrm{X})$ and $\mathrm{LCL}=\mathrm{X}-3 \sigma(\mathrm{X})$, where $\sigma(\mathrm{X})$ is the sample standard deviation. In an R- chart, the $\mathrm{CL}$ of the chart $\mathrm{R}$ is calculated as the average of the ranges of the subgroup where the range of a subgroup is the difference between maximum and minimum sample values. UCL and LCL of the range of the chart are RD4 and RD3 respectively, where D3 and D4 are appropriately calculated based on sample distribution range [9, $10,12]$.

\section{EXPERIMENTAL DETAILS}

42 bright Hull cell panels obtained from 42 different electroplating solutions were selected and subjected to color analysis. The total reflectance of the electroplated panels was measured with a UV spectrophotometer (CARY UV 50) equipped with a specular reflectance (SRA) attachment with a $6 \mathrm{~mm}$ circular opening. The reflectivity spectrum over the range of $380 \mathrm{~nm}$ to $830 \mathrm{~nm}$ for each electroplated panels were recorded and the color of the coatings was evaluated quantitatively by employing the Cary color software and recorded as $\mathrm{L}^{*} \mathrm{a}^{*} \mathrm{~b}^{*}$ value using a method based on $\mathrm{C}$ Illuminant and 2o visual field [11]. For the purpose of analysis, the electroplated hull cell panels was placed horizontally on the top of the SRA attachment as shown in Fig. 2 and the reflectance was measured at each location marked on the hull cell coupon as illustrated in Fig. 3.

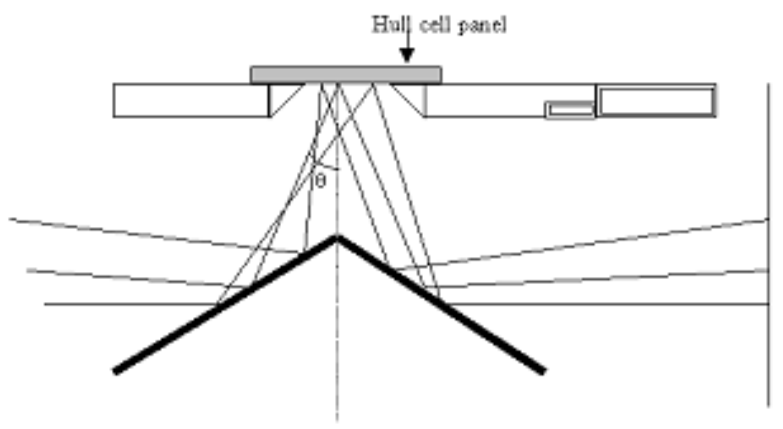

Figure2. Cross sectional schematic of fixed angle SRA, where $\theta$ is the angle of incidence to the surface

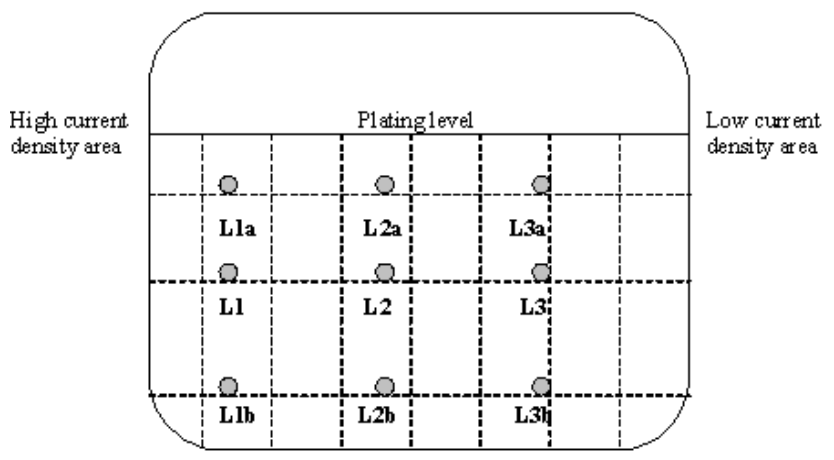

Note:

Approximate locations marked for measuring the reflectance

$\mathrm{L} 1, \mathrm{~L} 1 \mathrm{a}$ and $\mathrm{L} 1 \mathrm{~b}$ represent the area with the current density of $\sim 1.02 \mathrm{~A} \mathrm{dm}{ }^{-2}$

$\mathrm{L} 2, \mathrm{~L} 2 \mathrm{a}$ and $\mathrm{L} 2 \mathrm{~b}$ represent the area with the current density of $\sim 0.5 \mathrm{~A} \mathrm{dm}^{-2}$

$\mathrm{L} 3, \mathrm{~L} 3 \mathrm{a}$ and $\mathrm{L} 3 \mathrm{~b}$ represent the area with the current density of $\sim 0.074 \mathrm{~A} \mathrm{dm}^{-2}$

Figure3. Locations for measuring reflectance on electroplated Hull cell panel.

\section{RESULTS AND DISCUSSION}

All electroplated panels analyzed here are equally bright and are considered to meet the appearance specifications. During the measurement process, it was observed that the $\mathrm{L}^{*} \mathrm{a}^{*}$ and $b^{*}$ values recorded within the same current density area (e.g. L1a, L1 and L1b) appear to be very close to each other. In 
fact, their spectral reflectance curves were identical and overlap on each other. Therefore for the purpose of reporting the results, the values obtained at location L1, L2 and L3 were selected and used to calculate the $\Delta \mathrm{E}^{*} \mathrm{ab}$ between the locations. Since the color attributes have been quantified in terms of $\Delta \mathrm{E}^{*} \mathrm{ab}$, the range (R-) and mean (x-) for the control charts will be used to determine whether the majority of the samples analyzed were within the control limits or not.

In an R-chart, the range is the difference between the smallest $\Delta \mathrm{E}^{*} \mathrm{ab}$ and the largest $\Delta \mathrm{E}^{*} \mathrm{ab}$ in a panel. This range reflects the process variability instead of the tendency toward a mean value. The formulas for the determining control limits are as follows;

Upper Control Limit (UCL) $=$ D4R*

Lower Control Limit (LCL) $=$ D3 R*

$\check{\mathrm{R}}$ is the average range (and center line) for the samples

$\mathrm{R} *=\Sigma \mathrm{R} / \mathrm{k}$

Where $\mathrm{R}=$ range of each panels

$\mathrm{K}=$ number of samples

D3 and D4 are values from tables used for determining control limits that have been developed based on the range values [10].

For every electroplated panel analyzed, the most ideal condition is to have minimal or no variations in $\Delta \mathrm{E}^{*} \mathrm{ab}$ between the measured locations. However, it is almost impossible to produce no variations in color between one end to the other end of the panel measured. Therefore, it seems to be more practical to use the UCL in determining the acceptable limits for $\Delta \mathrm{E}^{*} \mathrm{ab}$ observed for the electroplated panels analyzed in this study.

For an (X-)-chart, the mean of $\Delta \mathrm{E}^{*} \mathrm{ab}$ measured on each panel is computed and plotted on the chart. The formulas for determining the control limits are as follows;

Upper Control Limit (UCL) $=\mathrm{X}+\mathrm{A} 2 \mathrm{R}^{*}$

Lower Control Limit $(\mathrm{LCL})=\mathrm{X}-\mathrm{A} 2 \mathrm{R}^{*}$

$\mathrm{X}$ is the average of the sample means (and center line) and $\mathrm{R}^{*}$ is the average of range value. A2 is a tabular value that is used to establish the control limits. Fig. 4 shows the $\mathrm{R}$ chart drawn with 42 sample ranges plotted on the chart. All points are within the control limits and the (R-) chart shows scatter points above and below the centerline reflecting the natural random variation in the $\Delta \mathrm{E}^{*}$ range [10]. Therefore, the $\Delta \mathrm{E}^{*}$ variables observed in the panels analyzed are in control. Since the $\mathrm{R}$ chart indicates that the $\Delta \mathrm{E}^{*}$ variables observed in the panel are in control, then the $\mathrm{X}$ chart is now constructed. The centerline is the mean of sample means. With $\mathrm{n}=3, \mathrm{~A} 2=$ 1.02 , the control limits calculated are:

UCL or $3 \sigma=$ xmean_of_means + A2 x Rmean $=4.691$

LCL or $-3 \sigma=$ xmean_of_means $-\mathrm{A} 2 \mathrm{x}$ Rmean $=0.428$

Figure 5 shows the $X$ chart drawn with 42 sample means plotted on the chart. The (X-) chart also shows scatter points above and below the centerline reflecting the natural random variations in the $\Delta \mathrm{E}^{*}$ average. Both the (R-) chart and (X-) chart are used together under the premise that both the $\Delta \mathrm{E}^{*}$ average and variability ( $\Delta \mathrm{E}^{*}$ range) must be in control for the color differences to be established. This is very logical since the two charts measure the process differently [10]. Since both the $\mathrm{X}$ and $\mathrm{R}$ charts exhibit no indications of being out of control, thus the control limits can be adopted as a statistical process control value for use as an acceptable color tolerance measured on the Hull cell panel. $\mathrm{UCL}(\mathrm{R})$ value of 5.37 obtained from the (R-) charts indicates that the difference of $\Delta \mathrm{E}^{*}$ up to 5.37 exists between the measured locations on the electroplated Hull cell panel produced in this study which can be considered to be within the acceptable process limit. Similarly, UCL (X) of 0.428 and 4.691 obtained from the (X-) charts indicates that the average $\Delta \mathrm{E}^{*}$ (from 0.428 to 4.691 ) measured at different locations on the electroplated Hull cell panels produced in this study is within the acceptable process limit. Therefore, if a bright panel analyzed using the same procedure gives $\Delta \mathrm{E}^{*}$ differences of 5.37 or less, it will still be considered that there is no visual color difference observed within that panel. Likewise if two electrodeposited panels were compared against each other whereby their $\Delta \mathrm{E}^{*}$ was found to be 5.37 or less, the color of both panels matches with each other.

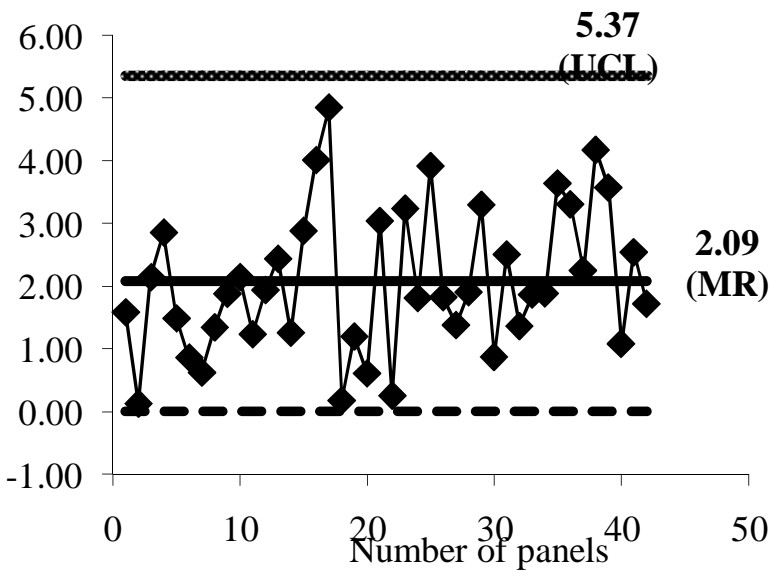

Figure4 R-chart of $\Delta \mathrm{E}^{*}$ of the electroplated Hull cell panels 


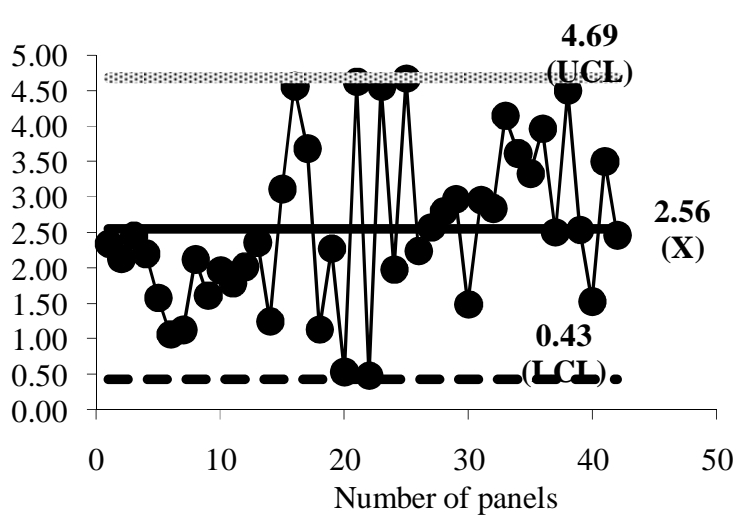

Figure5.X-chart of $\Delta \mathrm{E}^{*}$ of the electroplated Hull cell panels

\section{CONCLUSIONS}

Although there are numerous ways to specify color tolerances, one of the increasingly popular methods is using a total color difference method based on the CIELAB color scale [14]. By developing the control charts of $\Delta \mathrm{E}^{*} \mathrm{ab}$ range and average, the color tolerances between locations on a gold electrodeposited hull cell panels that have a bright appearance observed in this study were established. The $\Delta \mathrm{E}^{*} \mathrm{ab}$ for an 'acceptable' color match was found to be from 2.59 to 5.74. For the purpose of reporting the $\mathrm{L}^{*}, \mathrm{a}^{*}$ and $\mathrm{b}^{*}$ values for an electroplated hull cell panels, the average value of $\mathrm{L}^{*} \mathrm{a}^{*}$ and $\mathrm{b}^{*}$ measured from all locations in a panel should be used.

\section{ACKNOWLEDGEMENTS}

The work described here was supported by Universiti Sains Malaysia.

\section{REFERENCES}

[1]D. G. Foulke, (1974a). Introduction to electrolyte: In Gold Plating Technology (F. H. Reid, \& W. Goldie, ed.), p. 21- 24. England: Electrochem. Publ. Ltd.

[2]J. H. Lindsay, (2000a). Hull Cell Review. Plat. Surf. Finish. June. 10-13

[3]D. G. Foulke, (1974f). Electrolyte parameters: In Gold Plating Technology (F.H. Reid, \& W. Goldie, . ed.), p. 58-66. England: Electrochem. Publ. Ltd.

[4]R. W. Mackey, Cyanide zinc plating. In Modern Electroplating $3^{\text {rd }}$ edn. (F.A. Lowenheim, ed.), New York, London, Sydney, Toronto: John Wiley and Sonc Inc. (1975), p. 418-434.

[5]G. Normandeau, \& R. Roeterink, (1994). White Golds: A question of compromises, Conventional material properties compared to alternative formulations. Gold Bull. 27(3), 70-86 ] R.M. German, M. Guzowski, \& D.C. Wright, Gold Bull, (1994), 27(3), 113-116.
[6]C. Cretu, \& E. V. D. Lingen, (2000). Colored gold alloys. Gold Technol. 35, 31-40.

[7]KOCOUR. Directions for Hull Cell plating test. St. Louis, Chichago, Illinois: Kocour Company U.S.A. (1923).

[8]G. Raykhtsaum, \& D. P. Agarwal, (1997). The color of gold. Gold Technol. 22, 26-30

[9]LeaRonal Ltd. (1997). Expanded product guide: Decorative and precious metal industry. May, 1-5

[10]R.S. Russell, \& B. W. Taylor, (2000). Operation management. $3^{\text {rd }}$ edn. USA. Prentice Hall.

[11]M. Nose, M. Zhou, E. Honbo, M. Yokota, S. \& Saji, (2001). Colorimetric properties of $\mathrm{ZrN}$ and $\mathrm{Ti}$ coatings prepared by DC reactive sputtering. Surf. Coating Technol. 142-144, 211-217.

[12]D. C. Reddy, K. Ghosh, \& V. A. Vardhan, (1998). Identification and interpretation of manufacturing process patterns through neural networks. Mathl. Comput. Modelling. 27(5), 15-36

[13] R. M. German, M. Guzowski, \& D. C. Wright, (1980). The color of Gold-Silver-Copper alloys: Quantitative mapping of the ternary diagram. Gold Bull. 13(3), 113-116

[14] W. R. Harold, (2001). An introduction to appearance analysis. GATF Second Sight reprint (Cat. No. SS84), 7 pages.

\section{BIOGRAPHIES:}

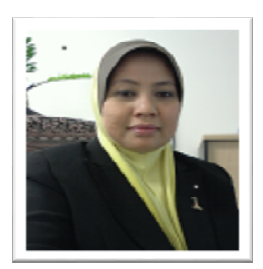

Che Wan Zanariah Che Wan Ngah (Ph.D in Analytical Chemistry) is a senior lecturer at Universiti Sains Islam Malaysia. Our research include formulations for gold plating and recovery of metals from the surface finishing industries by electro generative mode

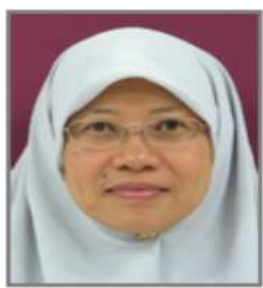

Norita Mohamed (Ph.D in Analytical Chemistry) is a professor at Universiti Sains Malaysia. We are involved in: Trace elements analyses particularly heavy metals in food, biological samples and environmental samples using atomic spectroscopy (instruments available: AAS, GFAAS, ICPMS).Removal and recycling of metals from electroplating wastes using batch and flow by electrochemical systems .Gold electroplating for decorative purposes. Enhancing the quality of teaching and learning of science especially chemistry. 